\title{
Effect of Selective Aldosterone Deficiency on Acidification in Nephron Segments of the Rat Inner Medulla
}

\author{
Thomas D. DuBose, Jr. and Carlton R. Caflisch
}

With the technical assistance of Galen W. Bevel and Cynthia J. Orlea

Division of Nephrology, University of Texas Medical Branch, Galveston, Texas 77550-2778

\begin{abstract}
Mineralocorticoid plays a role in urinary acidification and acid-base balance, but the response of the inner medulla to aldosterone has not been elucidated. A model of selective aldosterone deficiency (SAD) with hyperkalemia and hyperchloremic metabolic acidosis was employed to assess segmental acidification by measuring in situ pH, titratable acidity (TA) and total ammonia (Am). Hydrogen ion secretion was also examined as a function of the increment in in situ $\mathrm{PCO}_{2}$ in the collecting duct during bicarbonate loading. SAD rats were compared to ADX controls that received adrenalectomy and chronic replacement of gluco- and mineralocorticoid and to rats with chronic metabolic acidosis induced by oral $\mathrm{NH}_{4} \mathrm{Cl}$ (CMA). Both fractional and absolute delivery of Am to the loop of Henle was lower in SAD vs. CMA rats (1.34 to 3.63 $\mathrm{mM}, P<0.01)$. Delivery of Am to the base and tip collecting duct (BCD and TCD) was also markedly lower in SAD (1.50 vs. 0.52 and 1.77 vs. $0.47 \mathrm{mM}$, respectively, $P<0.01)$. Net addition of Am and net acid between BCD and TCD, observed in CMA rats, was not observed in SAD despite equivalent degrees of systemic metabolic acidosis. Similarly, the concentration gradient favoring transfer of $\mathrm{NH}_{3}$ between loop of Henle and CD was reduced in SAD. During bicarbonate loading the increment in $\mathrm{PCO}_{2}$ at $\mathrm{BCD}, \mathrm{TCD}$ and in final urine was significantly lower in SAD rats than in adrenal intact bicarbonate-loaded rats. Therefore, the acidification defect in this model of SAD appears to be a result of a decrease in ammonia production and delivery to the loop of Henle, impaired transfer from loop to collecting duct and reduction in the rate of $\mathrm{H}^{+}$ secretion by the collecting duct.
\end{abstract}

\section{Introduction}

Numerous studies in adrenalectomized (ADX) ${ }^{1}$ animals and human subjects have provided evidence that urinary acidifica-

\footnotetext{
Address reprint requests to Dr. DuBose, University of Texas Medical Branch, Division of Nephrology, 4.200 Old John Sealy E62, Galveston, TX 77550-2778.

Presented in part at the American Society of Nephrology 19th Annual Meeting, 7-10 1986, Washington, DC, and published in abstract form (Kidney Int. 31:407) and at the Annual Meeting of the American Society for Clinical Investigation, 29 April-2 May 1988, Washington, DC.

Received for publication 11 January 1988 and in revised form 22 June 1988.
}

J. Clin. Invest.

(c) The American Society for Clinical Investigation, Inc.

0021-9738/88/11/1624/09 \$2.00

Volume 82, November 1988, 1624-1632 tion, and systemic acid-base balance is influenced by mineralocorticoid elaboration by the adrenal cortex (1-4). The selective withdrawal of mineralocorticoid in this setting results in the development of metabolic acidosis concomitant with a reduction in urinary ammonium excretion $(1,3)$. These, and other studies, both in vivo and in vitro, have advanced the view that mineralocorticoid deficiency is an important cause of metabolic acidosis and impaired acidification even in the absence of renal disease or glucocorticoid deficiency.

Since the cortical collecting tubule is responsible for reabsorption of a portion of the filtered load of sodium by an aldosterone-dependent process, which increases transepithelial voltage favoring secretion of $\mathrm{K}^{+}$and $\mathrm{H}^{+}(5,6)$, it is of no surprise that aldosterone deficiency may cause hyperkalemia and metabolic acidosis. The outer medullary collecting duct has also been demonstrated to respond to aldosterone by increasing net hydrogen secretory capacity independent of sodium transport (electrogenic proton translocating ATPase) (7).

Less well defined, however, is the role of mineralocorticoid in acidification by the inner medullary collecting duct. Micropuncture studies have demonstrated that the rat papillary collecting duct is capable of bicarbonate reabsorption $(8,9)$. Recent studies of intracellular $\mathrm{pH}$ in rabbit papillary collecting duct cells in vitro suggest that active $\mathrm{H}^{+}$secretion is accomplished by a primary electrogenic $\mathrm{H}^{+}$pump (10). A Na ${ }^{+} / \mathrm{H}^{+}$ antiport has also been demonstrated recently (11) but the role of this transporter in transepithelial acidification has not been defined. Based on the observation of a diminution in the acid $\mathrm{pH}$ profile along the papillary collecting duct during acute acid loading in adrenalectomized rats with selective mineralocorticoid deficiency, the view that mineralocorticoid influences $\mathrm{H}^{+}$ secretion in this segment has been advanced (12). However, measurement of tubule fluid $\mathrm{pH}$ alone, without knowledge of urinary buffer excretion calls such an interpretation into question. Moreover, the possible impact of aldosterone deficiency on acidification parameters in the deep loop of Henle has not been studied previously.

The present study was designed, therefore, to investigate the role of aldosterone in acidification by accessible nephron segments of the rat inner medulla. Acidification was assessed by measurement of in situ $\mathrm{pH}$, titratable acidity, and total ammonia delivery during chronic metabolic acidosis, as well as by determination of papillary $\mathrm{PCO}_{2}$ during bicarbonate loading. (The terms ammonia and total ammonia indicate the sum of $\mathrm{NH}_{3}$ and $\mathrm{NH}_{4}^{+} . \mathrm{NH}_{3}$ indicates free base ammonia; $\mathrm{NH}_{4}^{+}$ indicates ammonium ion.)

1. Abbreviations used in this paper: ADX, adrenalectomy; Am, total ammonia; BCD, base papillary collecting duct; CMA, chronic metabolic acidosis; SAD, selective aldosterone deficiency; TA, titratable acidity; TCD, tip papillary collecting duct; TF/P, tubule to arterial plasma concentration ratio. 


\section{Methods}

Mutant Munich-Wistar rats weighing $85-155 \mathrm{~g}$ (mean, $132.7 \pm 0.02 \mathrm{~g}$ ) received commercial rat chow (Ralston Purina Co., St. Louis, MO) up to the time of micropuncture. To replace surgical fluid losses either $0.9 \% \mathrm{NaCl}$ or saline-bicarbonate $\left(120 \mathrm{mM} \mathrm{NaCl}, 25 \mathrm{mM} \mathrm{NaHCO}{ }_{3}\right.$, and $4 \mathrm{mM} \mathrm{KCl}$ ) equal to $2 \%$ of body weight was infused over $15 \mathrm{~min}$. An appropriate maintenance solution (as designated below) containing methoxy $\left[{ }^{3} \mathrm{H}\right]$ inulin was infused at $150 \mu \mathrm{Ci} / \mathrm{h}$ and adjusted to deliver a volume equal to $1 \%$ of body wt/h (groups I-III). Five experimental groups of rats were studied.

Group I. Adrenalectomy controls $(\mathrm{CON})(\mathrm{n}=25)$, were subjected to bilateral adrenalectomy (ADX) during pentobarbital anesthesia (5.0 $\mathrm{mg} / 100 \mathrm{~g}$ body wt i.p.) 4-6 d before micropuncture. An osmotic minipump (Alzet 2001; Alza Co., Palo Alto, CA) was implanted subcutaneously in the midscapular region at the time of ADX for delivery of both dexamethasone $\left(5.0 \mu \mathrm{g} \cdot 100 \mathrm{~g}\right.$ body $\left.\mathrm{wt}^{-1} \cdot \mathrm{d}^{-1}\right)$ and aldosterone $(0.8$ $\mu \mathrm{g} \cdot 100 \mathrm{~g}$ body $\left.\mathrm{wt}^{-1} \cdot \mathrm{d}^{-1}\right)(12,13)$. Animals in this group received tap water to drink until micropuncture commenced. Surgical fluid losses were replaced with a saline-bicarbonate solution containing both dexamethasone $\left(0.3 \mu \mathrm{g} \cdot 100 \mathrm{~g}\right.$ body $\left.\mathrm{wt}^{-1} \cdot \mathrm{h}^{-1}\right)$ and aldosterone $(0.5 \mu \mathrm{g} \cdot 100$ g body $\left.\mathrm{wt}^{-1} \cdot \mathrm{h}^{-1}\right)$.

Group II. Chronic metabolic acidosis (CMA) rats $(n=11)$ with intact adrenal function were subjected to a sham operation $5 \mathrm{~d}$ before micropuncture and received $0.30 \mathrm{M} \mathrm{NH}_{4} \mathrm{Cl}$ to drink. Isotonic saline was employed to replace surgical fluid losses and as a maintenance infusion during micropuncture.

Group III. Selective aldosterone deficiency (SAD) $(n=17)$ rats were subjected to ADX as in group I but only dexamethasone (5.0 $\mu \mathrm{g} \cdot 100 \mathrm{~g}$ body $\mathrm{wt}^{-1} \cdot \mathrm{d}^{-1}$ ) was infused via the osmotic minipump (13). Drinking water was $0.9 \% \mathrm{NaCl}$ containing $1.2 \%$ dextrose. After recovery from surgery consumption of food and drinking water was a prerequisite for micropuncture. Rats that did not gain weight as compared to groups I and II were rejected. Premicropuncture surgical losses were replaced with $0.9 \% \mathrm{NaCl}$ to which dexamethasone $(0.3 \mu \mathrm{g} \cdot 100 \mathrm{~g}$ body $\left.\mathrm{wt}^{-1} \cdot \mathrm{h}^{-1}\right)$ was added. Five additional mineralocorticoid-deficient rats were studied in which higher delivery of titratable acid to the base of the collecting duct was accomplished (III-B, SAD-HP). Rats in this group were slightly larger $(130 \pm 10$ vs. $114 \pm 5 \mathrm{~g})$ than the 17 rats in group III, and consumed a larger mean daily weight of food. Findings in this group allow evaluation of the effect of non-Am buffer delivery on net acidification in the inner medullary collecting duct during aldosterone deficiency.

Group IV. Control-bicarbonate loaded rats $\left(\mathrm{CON}-\mathrm{HCO}_{3}\right)(n=25)$ were adrenal intact normal controls that received a hypertonic sodium bicarbonate solution $(300 \mathrm{mM} \mathrm{NaHCO}, 25 \mathrm{mM} \mathrm{KCl})$ at a rate equal to $1.8 \%$ body wt/h for $2.0 \mathrm{~h}$ before micropuncture or until stability of urine $\mathrm{pH}$ and $\mathrm{PCO}_{2}$ was assured as described previously (14). Rats in this group were subjected to papillary micropuncture and were employed to determine urinary and papillary $\mathrm{PCO}_{2}$ as described previously (14).

Group $V$. Selective aldosterone deficiency/bicarbonate-loaded rats $\left(\mathrm{SAD}-\mathrm{HCO}_{3}\right)(n=10)$ were subjected to adrenalectomy and received a chronic maintenance infusion of dexamethasone by osmotic minipump exactly as in group III. $2 \mathrm{~h}$ before micropuncture, sodium bicarbonate was infused as in group IV. Since tubule fluid was not collected, a volume marker was not employed in this or the preceding group (IV). Stability of urine $\mathrm{pH}$ and $\mathrm{PCO}_{2}$ was assured as in group IV.

All rats were anesthetized for micropuncture by intraperitoneal injection of $100 \mathrm{mg} \cdot \mathrm{kg}$ body $\mathrm{wt}^{-1}$ Inactin (BYK-Gulden, Konstanz, Federal Republic of Germany) and placed on a thermostatically controlled $\left(37^{\circ} \mathrm{C}\right)$ micropuncture table. Surgical exposure of the extrarenal papilla and papillary micropuncture was accomplished exactly as described previously $(9,14)$. Arterial blood acid-base status was carefully monitored and maintained as described previously (9).

Whole kidney excretion was assessed by collection of bladder urine (right, untouched kidney) for determination of glomerular filtration rate, $\mathrm{pH}, \mathrm{PCO}_{2}$, titratable acidity, and total ammonia. Arterial blood gases were monitored and maintained as described previously $(9,14)$. Tubule fluid samples from the bend of Henle's loop (ascending and descending limbs) and from the base and tip of the papillary collecting duct were collected as described previously (15). The length of exposed papilla between base and tip collecting duct sites was measured with an ocular micrometer and averaged $2.50 \pm 0.4 \mathrm{~mm}$ in all groups and did not differ between groups $(P>0.05)$.

Analysis. Arterial pH, $\mathrm{PCO}_{2}$ and bicarbonate concentration and urine $\mathrm{pH}$ were determined using a blood gas analyzer (model 165-2; Corning Medical, Corning Glass Works, Medfield, MA). Urine volume was determined by weighing. Methoxy $\left[{ }^{3} \mathrm{H}\right]$ inulin activity in plasma, urine, and tubule fluid was determined in a liquid scintillation counter (Rackbeta 1211; LKB/Wallac, Turku, Finland) using a gel suspension made with Ready-Solv MP (Beckman Instruments, Inc., Fullerton, CA). Radioactivity in micropuncture samples were determined on a portion of each sample (5-20 nl) measured in a constant bore capillary. The remainder of each sample was used for measurement of titratable acidity and total ammonia. Urine samples $(0.1 \mathrm{ml})$ were diluted in equal volumes of $0.1 \mathrm{HCl}$, in order to dissipate $\mathrm{HCO}_{3}^{-}$ as $\mathrm{CO}_{2}$, and were then pipetteted into a vial containing $1.8 \mathrm{ml}$ of $\mathrm{H}_{2} \mathrm{O}$. The sample was then titrated with $0.1 \mathrm{~N} \mathrm{NaOH}$ to a $\mathrm{pH}$ equal to systemic arterial blood $\mathrm{pH}$ with a standard macrotitrator (Radiometer model ETS 81 1; London Co., West Lake, $\mathrm{OH})(16,17)$. Formaldehyde ( $37 \%$ solution) was then added $(0.1 \mathrm{ml})$ to liberate $\mathrm{H}^{+}$and the sample was backtitrated to blood $\mathrm{pH}$ to estimate the total ammonia concentration [Am] (17).

In situ pH in tubule fluid of inner medullary nephron segments was measured using single-barreled glass membrane microelectrodes as described previously (9). The electrodes were always calibrated before and after use in vivo in standard buffers of $\mathrm{pH} 7.40$ and 6.00 at $37^{\circ} \mathrm{C}$. Transepithelial voltage of the inner medullary collecting duct and loop of Henle has a negligible effect on potential recorded by single-barreled pH microelectrodes (9). $\mathrm{PCO}_{2}$ was measured with $\mathrm{PCO}_{2}$ microelectrodes of $15-20 \mu \mathrm{m}$ tip diameter as routinely manufactured in our laboratory and described in detail previously (14). Calibration in three analytically balanced gases was performed as described previously (14) before and after each set of data collections $(n=4-6)$ by direct puncture of the base papillary collecting duct or by insertion into the opening of the tip of the papillary collecting duct.

Titratable acidity [TA] and total ammonium [Am] in tubule fluid was determined by microtitration as modified by our laboratory from the method described by Karlmark (18). Specifically, a computerbased titration system (Picolab-2; Idea Computers, Richmond, TX) was used. Tubule fluid (2-10 $\mathrm{nl})$, diluted 1:20 with deionized distilled water, was deposited under oil on a siliconized glass slide. Initial pH was determined by a double-barreled glass membrane $\mathrm{pH}$ microelectrode manufactured in our laboratory (15-20 $\mu \mathrm{m}$ tip diam). This input was provided to the computer as a start point for titration of the sample. Constant current $(0.500$ mamps) was then pulsed intermittently (from 0.002 to $2 \mathrm{~s}$ ) by the computer-controlled circuit through an antimony $(\mathrm{Sb})$ electrode (referenced by a separate Ling-Gerard electrode) to liberate $\mathrm{OH}^{-}$into the droplet as follows: $\mathrm{Sb}_{2} \mathrm{O}_{3}+3 \mathrm{H}_{2} \mathrm{O}$ $+6 \mathrm{e} \rightarrow 2 \mathrm{Sb}+60 \mathrm{H}^{-}$.

Current pulsed intermittently obviates the need for a stirring mechanism. The current utilized in the titration process was measured automatically and the amount of current required to titrate the sample to the desired endpoint (rat arterial blood pH) is proportional to the [TA] as defined by a series of standards. When performed in this manner, titrations determined with the microtitrator are identical to values obtained with known standards as well as to urine as measured by standard macrotitration (Fig. $1 \mathrm{~A}$ ). Formaldehyde $(37 \%)$ was then added to the sample droplet (10-15\% of droplet volume) to liberate additional $\mathrm{H}^{+}$. The sample was then retitrated to the same $\mathrm{pH}$ end point. Values for total ammonium concentration [Am] determined in this manner compare favorably to standard macrotitration (Fig. $1 \mathrm{~B}$ ).

Calculations. Net acid excretion (NAE) of tubule fluid (and urine) was calculated as: $\mathrm{NAE}=\mathrm{TA}+\mathrm{Am}-\mathrm{HCO}_{3}^{-}$, where TA is titratable acid, Am is total ammonia, and $\mathrm{HCO}_{3}^{-}$is any bicarbonate in the 


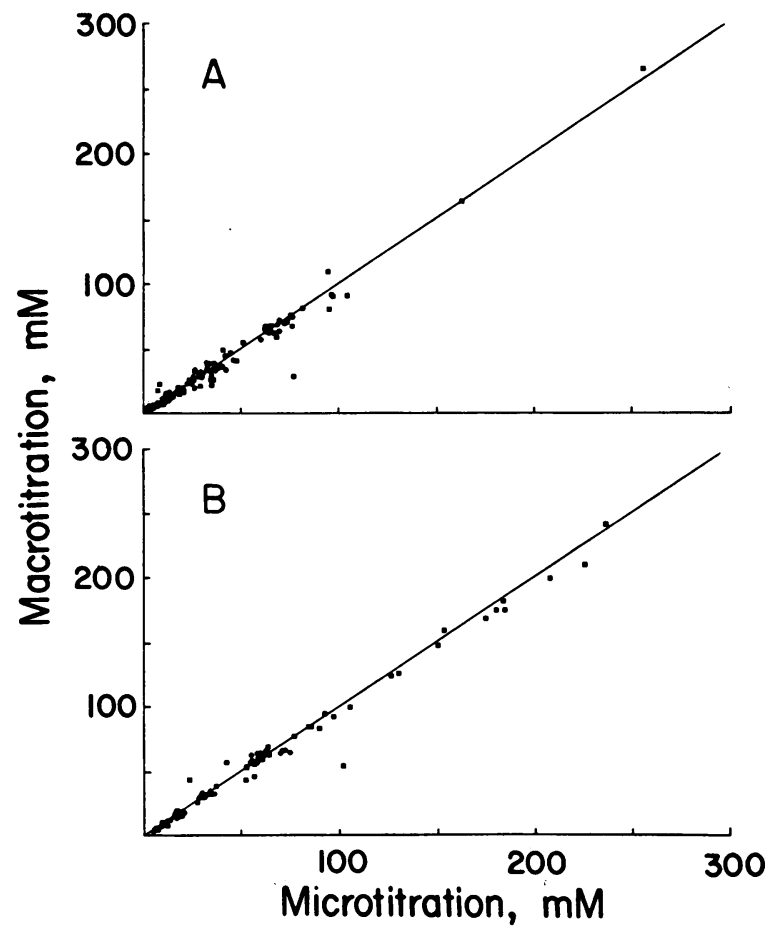

Figure 1. Comparison of titratable acid $(A)$ and ammonium concentrations $(B)$ as determined by microtitration technique (described in Methods) vs. macrotechnique in known standard solutions (closed circles) and rat urine (closed squares). For $A: r=0.99, P<0.001$, and for $B: r=0.98, P<0.001$.

sample. Bicarbonate concentration was calculated from in situ $\mathrm{pH}$ and $\mathrm{PCO}_{2}$. Acid indices for titratable acid, ammonia, and net acid were calculated from the respective concentrations in tubule fluid $\left[\mathrm{TF}_{\mathrm{x}}\right]$, factored by the ratio of tubule fluid to plasma inulin: $\left[\mathrm{TF}_{\mathrm{x}}\right] /\left[\mathrm{TF} / \mathrm{P}_{\mathrm{In}}\right]$

Absolute delivery of ammonia, titratable acid, and net acid to the loop of Henle were calculated from single nephron flow rates $(\dot{V})$ and the respective $\left[\mathrm{TF}_{\mathrm{x}}\right]$ at the loop as described previously (15). Absolute deliveries to base and tip collecting duct were estimated from right whole kidney glomerular filtration rate (GFR) as follows: Abs. Del. $x$ $=\left(\mathrm{GFR} /(\mathrm{TF} / \mathrm{P})_{\mathrm{In}_{\mathrm{n}}}\right)\left[\mathrm{TF}_{\mathrm{x}}\right]$. Where $\left[\mathrm{TF}_{\mathrm{x}}\right]=$ total ammonia, $\mathrm{TA}$, or net acid concentration in tubule fluid.

Concentrations of free base ammonia $\left[\mathrm{NH}_{3}\right]$ in loop of Henle, base and tip collecting duct were calculated from the measured total ammonia concentration and in situ $\mathrm{pH}$ employing the Henderson-Hasselbalch equation from the $\mathrm{pK}_{\mathrm{a}}^{\prime}$ corrected for ionic strength as described in detail previously (15).

Data are expressed as mean values, and differences between means were analyzed using the Student's $t$ test for paired or unpaired data as appropriate. $P<0.05$ were considered significant.

\section{Results}

The parameters mean body weight, arterial blood pressure, hematocrit, the number of days between initial surgery and papillary micropuncture, and length of exposed papilla were similar in all groups. Systemic arterial blood gas and electrolyte values are displayed in Table I for groups I-III. Group II rats received $\mathrm{NH}_{4} \mathrm{Cl}$ to induce metabolic acidosis of similar magnitude to that observed spontaneously with selective aldosterone deficiency (SAD-III). $\mathrm{pH}$ and total $\mathrm{CO}_{2}$ concentrations were significantly and equally reduced in groups II and III as compared to adrenalectomized-dexamethasone and aldosterone replete controls (group I-CON). Furthermore, the plasma
Table I. Systemic Acid Base and Electrolyte Data

\begin{tabular}{lccccc}
\hline Group & \multicolumn{1}{c}{$\mathrm{pH}$} & $\mathrm{PaCO}_{2}$ & \multicolumn{1}{c}{$\mathrm{tCO}_{2}$} & $\mathrm{Na}^{+}$ & \multicolumn{1}{c}{$\mathrm{K}^{+}$} \\
\hline & & $m m H g$ & meq/liter & meq/liter & meq/liter \\
& & & & & \\
I CON & $7.31 \pm 0.28$ & $41 \pm 1.7$ & $21.1 \pm 0.8$ & $141 \pm 1.3$ & $4.9 \pm 0.3$ \\
II CMA & $7.19 \pm 0.01^{*}$ & $43 \pm 1.3$ & $17.1 \pm 0.5^{*}$ & $146 \pm 0.7$ & $4.6 \pm 0.1$ \\
III SAD & $7.20 \pm 0.01^{*}$ & $40 \pm 1.5$ & $18.0 \pm 0.5^{*}$ & $143 \pm 1.3$ & $5.8 \pm 0.3^{* \ddagger}$
\end{tabular}

Data displayed as mean values \pm SEM.

${ }^{*} P<0.01$ vs. controls; ${ }^{\ddagger} P<0.01$ group II vs. group III.

$\left[\mathrm{K}^{+}\right]$was significantly higher in SAD rats $(5.8 \mathrm{meq} / \mathrm{liter})(P$ $<0.01$ ).

Right whole kidney data are displayed in Table II. Urine $\mathrm{pH}$ was significantly lower in SAD rats $(5.42 \pm 0.08, P<0.01)$ but glomerular filtration rates were indistinguishable in all three groups. Titratable acid excretion did not increase in CMA rats as compared to controls but was reduced significantly in SAD rats. As expected, chronic metabolic acidosis resulted in a marked increase in urinary ammonium excretion $475 \pm 52$ to $1,219 \pm 70 \mathrm{neq} / \mathrm{min}, P<0.01$ ), but not in rats with selective aldosterone deficiency (group III: $359 \pm 34 \mathrm{neq} / \mathrm{min}, P$ $<0.01)$ despite a similar degree of acidemia. Thus net acid excretion (not shown in table) was equal to $811 \pm 81 \mathrm{neq} / \mathrm{min}$ in group I, $1532 \pm 112 \mathrm{neq} / \mathrm{min}$ in group II, and $561 \pm 57 \mathrm{neq} /$ min in group III.

\section{Micropuncture findings}

Collecting duct. Micropuncture data for the base and tip of the collecting duct (BCD and TCD) are summarized in Table III. pH declined significantly from base to tip collecting duct in CMA rats (group II) $(6.38 \pm 0.06$ to $6.24 \pm 0.05 \mathrm{U})$ as well as in group III (6.35 \pm 0.08 to $6.11 \pm 0.06 \mathrm{U})$ and III, $B(6.27 \pm 0.17$ to $5.70 \pm 0.05)$, but not in group $I$. The total ammonia concentration at both base and tip was higher during chronic metabolic acidosis (group II) than in either control (group I) or SAD rats (group III), while titratable acid concentration was lower in SAD rats at both $\mathrm{BCD}$ and TCD. In group III, $B$, however, the concentration of titratable acid, but not total ammonia was higher than in group III but similar to groups I and II at both base and tip.

To assess net transport of TA, Am, and net acid (NA) along the collecting duct, changes in concentration were factored for net water movement by dividing tubule fluid concentrations by $T F / P$ inulin values. The resulting ratio is a measure of the relative amount of TA, Am, or NA present at the base and tip micropuncture sites (15). Acid indices for TA, Am, and NA did not change from base to tip in control rats. During chronic

Table II. Right Whole Kidney Data

\begin{tabular}{ccccccc}
\hline Group & Urine pH & GFR & {$[\mathrm{TA}]$} & [Am] & $\mathrm{U}_{\mathrm{TA}} \mathrm{V}$ & $\mathrm{U}_{\text {Am }} \mathrm{V}$ \\
\hline & $U$ & $\mu l /$ min & meq/liter & meq/liter & neq/min & neq/min \\
I CON & $5.76 \pm 0.05$ & $647 \pm 49$ & $60.8 \pm 5.2$ & $91.2 \pm 7.5$ & $336 \pm 38$ & $475 \pm 52$ \\
II CMA & $5.66 \pm 0.11$ & $761 \pm 45$ & $48.2 \pm 7.6^{*}$ & $176.6 \pm 11.9^{*}$ & $312 \pm 54$ & $1219 \pm 70$ \\
III SAD & $5.42 \pm 0.08^{*}$ & $605 \pm 50$ & $29.5 \pm 3.9^{* \pm}$ & $58.1 \pm 5.4^{* \neq}$ & $202 \pm 42^{* \pm}$ & $359 \pm 34^{\ddagger}$
\end{tabular}

Data displayed as mean values $\pm \mathrm{SEM},{ }^{*} P<0.01$ vs. controls; ${ }^{\ddagger} P<0.01$ group II vs. group III.

$\mathrm{UV}$, urine flow rate; and GFR, glomerular filtration rate. 


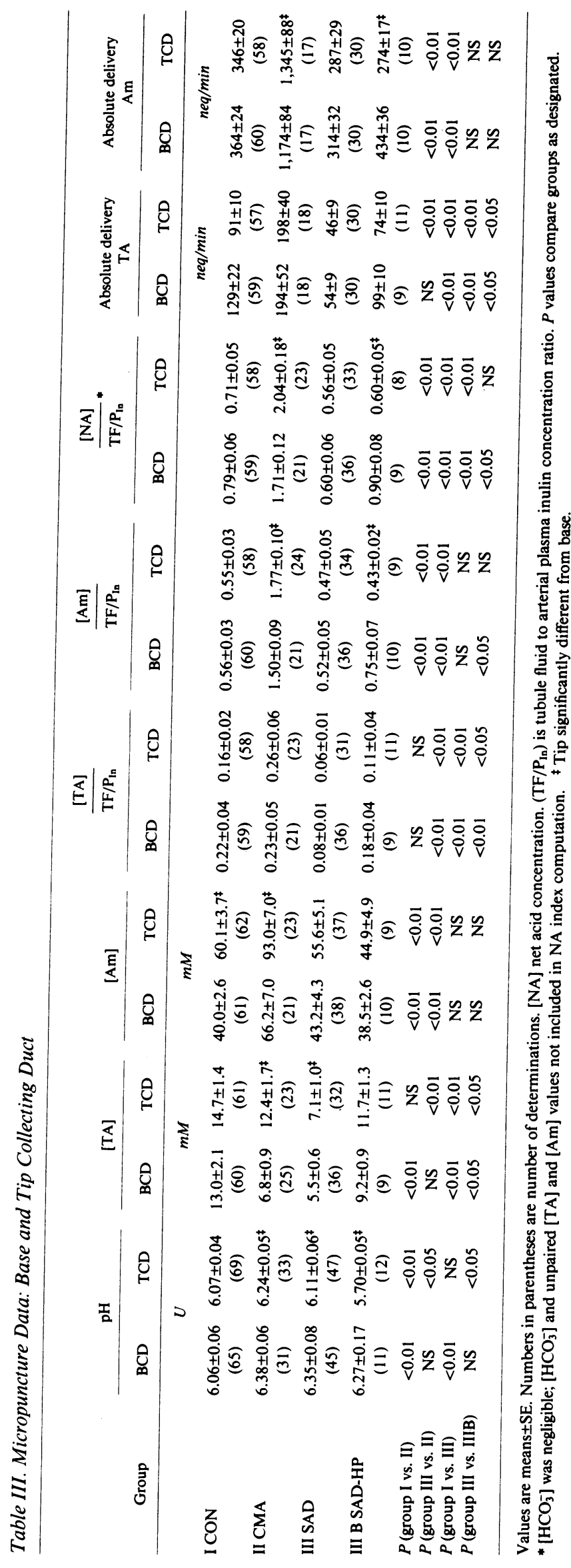

metabolic acidosis (group II) the ammonia index increased significantly, indicating net addition of ammonia from base to tip $(1.50 \pm 0.09$ to $1.77 \pm 0.10 \mathrm{mM}, P<0.01)$ (Fig. 2). In contrast, values were lower in SAD rats at both sites when compared to group II $(0.52 \pm 0.05$ to $0.47 \pm 0.05, P<0.01)$. Moreover, there was no detectable net acid transport along the terminal portion of the collecting duct in SAD rats $(P>0.05)$ while net addition of net acid was apparent in group II $(1.71 \pm 0.12$ to $2.04 \pm 0.18)$ (Table III and Fig. 2). Values for absolute delivery, estimated from whole kidney GFR values as described in Methods, corroborated the fractional data (Fig. 3). Absolute delivery of ammonia was dramatically higher at the BCD during chronic metabolic acidosis when compared to either group I or III, and increased further along the length of the duct $(1,174 \pm 84$ to $1,335 \pm 89 \mathrm{neq} / \mathrm{min}, P<0.01)$. These values were markedly lower in SAD rats and net addition was not observed (314 \pm 32 to $287 \pm 29 \mathrm{neq} / \mathrm{min})$.

Loop of Henle. Micropuncture data for the loop of Henle are summarized in Table IV. Loop $\mathrm{pH}$ was significantly more acid in group II but equal in groups I and III (7.27 \pm 0.04 , vs. $7.35 \pm 0.06$, and $7.31 \pm 0.04)$. Ammonium concentration increased during metabolic acidosis $(8.0 \pm 0.9$ to $17.3 \pm 3.3 \mathrm{mM})$ but declined in SAD rats $(9.8 \pm 1.6, P<0.01)$. Tubule flow rate $(\dot{V})$ was greater and $T F / P_{I n}$ lower during chronic metabolic acidosis (group II). The amount of ammonia delivered to the loop of Henle (indicated by $[\mathrm{Am}] /\left(\mathrm{TF} / \mathrm{P}_{\mathrm{In}}\right)$ ) was greater in group II but declined by $40 \%(3.63 \pm 0.68$ to $1.34 \pm 0.29 \mathrm{mM})$ with selective aldosterone deficiency (group III) and to $1.65 \pm 0.39$ in group III, $B(P<0.01)$. The titratable acid fraction was similar in groups I-III but higher in group III, $B$. Values for [TA] in the loop of Henle during chronic metabolic acidosis were identical to values reported by Buerkert (19) in adrenal intact acid-loaded rats. Values for total ammonia concentration and the ammonium index at the loop of Henle were (Fig. 2) slightly higher than that reported from our laboratory, in adrenal intact control rats (15) and slightly less than that reported by others (19) in the same physiologic condition. Nevertheless, the net acid index and absolute net acid delivery (Fig. 3) were similar in our group I rats and adrenal intact controls reported by others (19).

$\mathrm{NH}_{3}$ concentration gradients in inner medulla. Calculated $\mathrm{NH}_{3}$ concentration values for all groups at each site are summarized in Table V. Ammonia concentration increased at the base collecting duct after chronic metabolic acidosis in adrenal intact and aldosterone-deficient rats (groups II and III vs. group I), but remained significantly higher at the tip collecting duct only in CMA rats (group I: $83 \pm 8$ vs. group II: $186 \pm 32$ vs. group III. $125 \pm 22 \mu \mathrm{M}$ ). The ammonia concentration at the loop of Henle was higher in group II rats $(265 \pm 41 \mu \mathrm{M})$ than in either group I $(122 \pm 11 \mu \mathrm{M})$ or group III $(192 \pm 29, P<0.01)$. In each group the $\mathrm{NH}_{3}$ concentration in the loop of Henle was significantly higher than the average concentration in the collecting duct but the magnitude of this difference was dramatically lower in SAD $(49 \pm 20 \mu \mathrm{M})$ as compared to CMA rats $(105 \pm 28 \mu \mathrm{M})(P<0.01)$.

$\mathrm{PCO}_{2}$ data. During acute bicarbonate loading urine $\mathrm{pH}$ was equally alkaline in adrenal intact controls and in aldosteronedeficient rats (Table VI). Urine $\mathrm{PCO}_{2}$ and the U-B $\mathrm{PCO}_{2}$ difference was significantly lower in rats with selective aldosterone deficiency $(118$ vs. $84 \mathrm{mmHg}$ and 70 vs. $41 \mathrm{mmHg}$, respectively, $P<0.01$ ). Values for $\mathrm{PCO}_{2}$ in the micropuncture papillary collecting duct of adrenal intact bicarbonate loaded rats 


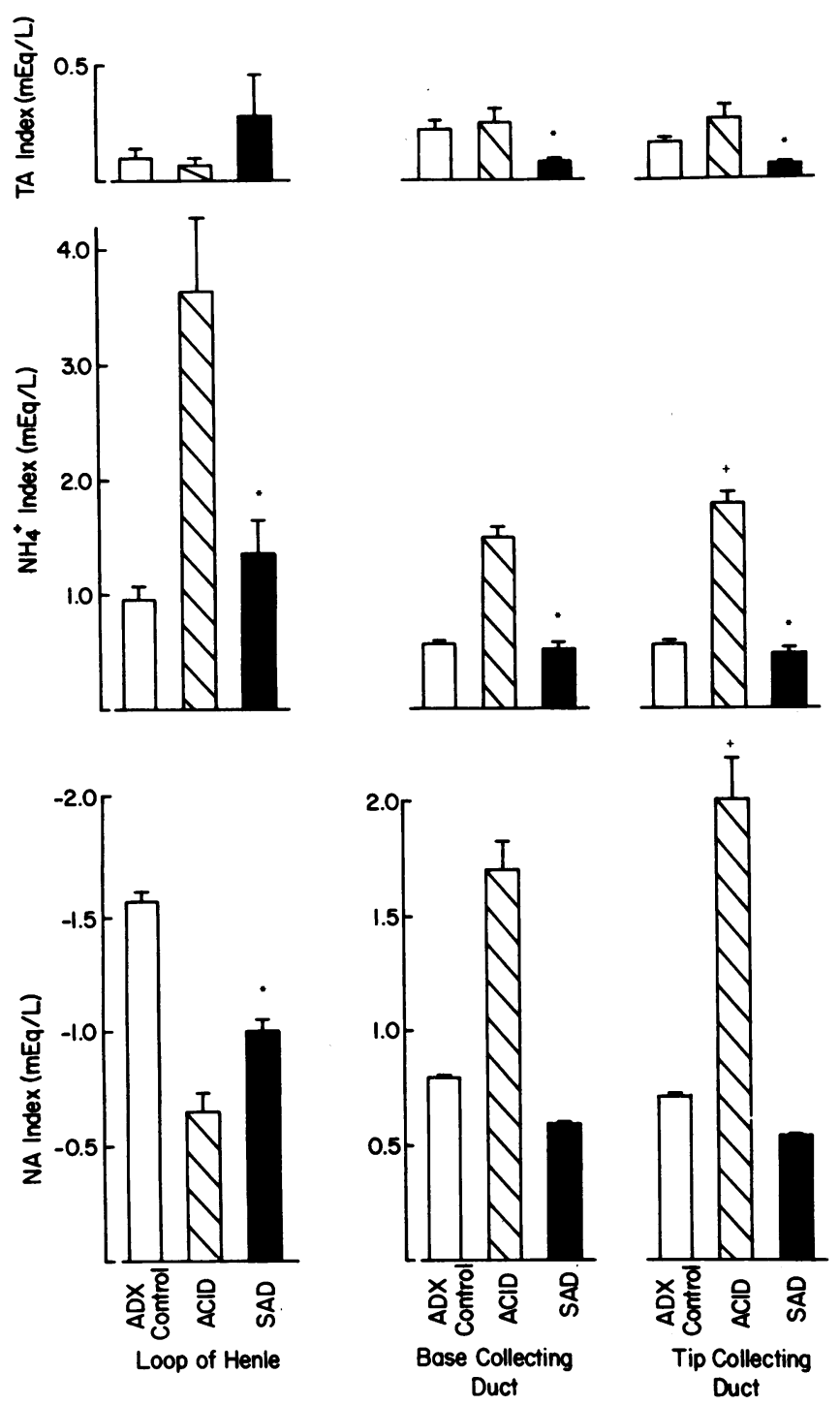

Figure 2. Amount of TA (top panel), total ammonia $\left(\mathrm{NH}_{4}^{+}\right)$(middle panel) and net acid (NA) (lower panel) delivered to each micropuncture site (abscissa) for groups I-III: ADX-control (clear bars), CMA (hatched bars) and SAD (solid bars). ${ }^{*} P<0.01$ for SAD vs. CMA. ${ }^{+} P<0.05$ for tip values $>$ base values in CMA.

were significantly above arterial blood levels, as has been observed previously in our laboratory (14). Moreover, $\mathrm{PCO}_{2}$ increased from base to tip collecting duct $(82 \pm 5$ to $118 \pm 3$ $\mathrm{mmHg}, P<0.01$ ). In contrast, the $\mathrm{PCO}_{2}$ at both base and tip collecting duct in SAD-NaHCO -loaded rats, was significantly less than the values observed in controls $(64 \pm 2$ to $80 \pm 3$ mmHg, $(P<0.01)$ (Table VI and Fig. 4). A reduction in $\mathrm{PCO}_{2}$ at the base and tip of the papillary collecting duct during bicarbonate loading has been demonstrated previously to be a reliable index of impaired $\mathrm{H}^{+}$secretion (14).

\section{Discussion}

The effect of aldosterone deficiency on renal acidification has been examined previously in adrenalectomized dogs by carefully executed balance techniques during chronic postoperative replacement of glucocorticoid and mineralocorticoid hor-
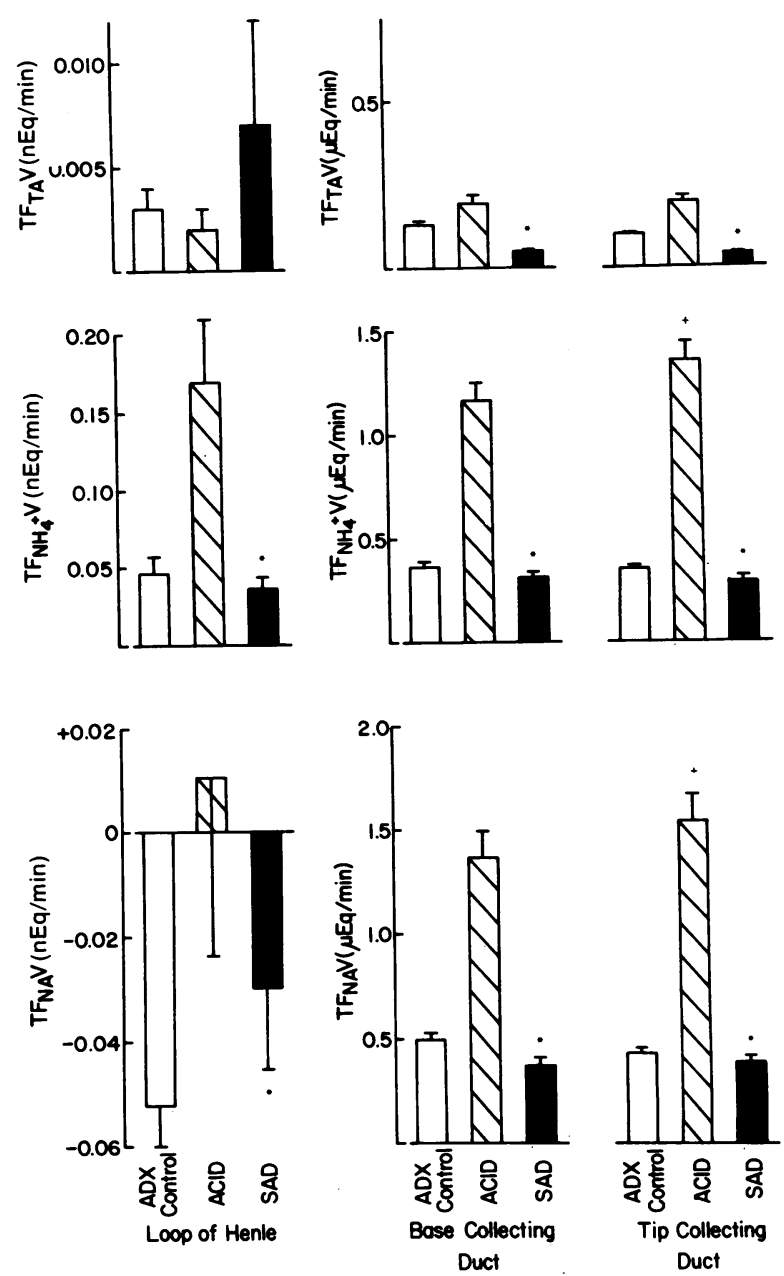

Figure 3. Absolute delivery of $\mathrm{TA}, \mathrm{NH}_{4}^{+}$, and NA to each micropuncture site. Notation same as Fig. 2.

mones $(1,2,4)$. Selective discontinuation of mineralocorticoid was associated with a decline in net acid excretion and the development of a hyperchloremic-hyperkalemic metabolic acidosis (1). The reduction in net acid excretion was attributed to a marked decline in ammonium excretion. Moreover, ammonium excretion (and presumably production) could be modulated in response to plasma potassium levels since ammonium excretion was diminished to a lesser extent when hyperkalemia was prevented. Segmental ammonium transport has not been examined previously in an experimental model of selective aldosterone deficiency by micropuncture techniques so that changes in ammonium transport, as opposed simply to a decrease ammonia production, as would be expected with hyperkalemia $(1,20,21)$, have not been considered.

Studies in adrenalectomized dogs (4) and man (3) have suggested that aldosterone deficiency impairs the rate at which hydrogen secretion proceeds in the collecting duct, while the ability to maintain a normal $\mathrm{pH}$ gradient between urine (collecting duct) and blood is unimpaired. Such a view is based on the observation that urine $\mathrm{pH}$ in dogs with aldosterone deficiency is low during periods of reduced buffer excretion but increases above that observed in mineralocorticoid replete dogs when buffer excretion is increased $(1,4,22)$. Nevertheless, a segmental analysis of acidification in selective aldosterone deficiency has not been reported previously. 
Table IV. Micropuncture Data: Loop of Henle

\begin{tabular}{|c|c|c|c|c|c|c|c|}
\hline Group & $\mathrm{pH}$ & {$[\mathrm{TA}]$} & [Am] & $\mathrm{TF} / \mathbf{P}_{\mathrm{In}}$ & $\dot{\mathbf{v}}$ & $\frac{[\mathrm{TA}]}{\mathrm{TF} / \mathrm{P}_{\mathrm{In}}}$ & $\frac{[\mathrm{Am}]}{\mathrm{TF} / \mathbf{P}_{\mathrm{ln}}}$ \\
\hline & $U$ & $m M$ & $m M$ & & $n l / m$ & $m M$ & $m M$ \\
\hline I CON & $\begin{array}{c}7.35 \pm 0.06 \\
(7)\end{array}$ & $\begin{array}{c}0.71 \pm 0.23 \\
(27)\end{array}$ & $\begin{array}{c}8.0 \pm 0.9 \\
(27)\end{array}$ & $\begin{array}{c}6.92 \pm 0.55 \\
\quad(31)\end{array}$ & $\begin{array}{c}5.91 \pm 0.62 \\
(37)\end{array}$ & $\begin{array}{c}0.11 \pm 0.04 \\
(26)\end{array}$ & $\begin{array}{c}0.96 \pm 0.12 \\
(23)\end{array}$ \\
\hline II CMA & $\begin{array}{c}7.27 \pm 0.04^{*} \\
(10)\end{array}$ & $\begin{array}{c}0.41 \pm 0.25 \\
\quad(14)\end{array}$ & $\begin{array}{c}17.3 \pm 3.3^{*} \\
(13)\end{array}$ & $\begin{array}{c}4.81 \pm 0.66^{*} \\
(15)\end{array}$ & $\begin{array}{c}9.87 \pm 1.20^{*} \\
(17)\end{array}$ & $\begin{array}{c}0.07 \pm 0.03 \\
(14)\end{array}$ & $\begin{array}{c}3.63 \pm 0.68^{*} \\
(14)\end{array}$ \\
\hline III SAD & $\begin{array}{c}7.31 \pm 0.04^{\ddagger} \\
\text { (7) }\end{array}$ & $\begin{array}{c}1.18 \pm 0.58^{\ddagger} \\
(26)\end{array}$ & $\begin{array}{c}9.8 \pm 1.6^{\ddagger} \\
(23)\end{array}$ & $\begin{array}{c}7.79 \pm 0.78^{\ddagger} \\
(25)\end{array}$ & $\begin{array}{c}4.78 \pm 0.52^{\ddagger} \\
\quad(27)\end{array}$ & $\begin{array}{c}0.28 \pm 0.18 \\
(23)\end{array}$ & $\begin{array}{c}1.34 \pm 0.29^{\ddagger} \\
\quad(23)\end{array}$ \\
\hline III B SAD-HP & $\begin{array}{l}7.34 \pm 0.04^{\ddagger} \\
(5)\end{array}$ & $\begin{array}{c}1.84 \pm 0.63^{\ddagger} \\
(12)\end{array}$ & $\begin{array}{c}11.4 \pm 2.3^{\ddagger} \\
(12)\end{array}$ & $\begin{array}{c}8.18 \pm 0.9^{\ddagger} \\
(12)\end{array}$ & $\begin{array}{c}4.26 \pm 0.49 \\
(12)\end{array}$ & $\begin{array}{c}0.48 \pm 0.12^{*} \\
(12)\end{array}$ & $\begin{array}{c}1.65 \pm 0.39^{\ddagger} \\
\text { (12) }\end{array}$ \\
\hline
\end{tabular}

${ }^{*} P<0.01$ vs. group $\mathrm{I},{ }^{\ddagger} P<0.01$ vs. group II. $\dot{\mathrm{V}}$ indicates tubule flow rate; [Am] total ammonia concentration, and [TA] titratable acid concentration.

The present study was designed to investigate acidification parameters in nephron segments of the inner medulla during selective aldosterone deficiency in two physiologic settings employing two techniques. First, titratable acid and total ammonia delivery was measured during the chronic metabolic acidosis that accompanied selective aldosterone deficiency. Second, papillary $\mathrm{PCO}_{2}$ was measured directly with a $\mathrm{PCO}_{2}$ microelectrode during bicarbonate infusion as an index of terminal nephron $\mathrm{H}^{+}$secretion. Several new findings emerge from these studies: (a) Delivery of total ammonia to the loop of Henle, as well as to the base and tip collecting duct, was markedly reduced after selective aldosterone deficiency. (b) In the face of a comparable degree of systemic metabolic acidosis, net addition of ammonium between the base and tip of the papillary collecting duct, as observed in chronic metabolic acidosis, was obliterated in selective aldosterone deficiency. (c) Accompanying the absence of ammonium addition to the collecting duct during aldosterone deficiency, the concentration gradient for free-base $\mathrm{NH}_{3}$ was less favorable for diffusive transfer from loop of Henle to collecting duct. $(d)$ Both papillary $\mathrm{PCO}_{2}$ measured in situ, and urinary $\mathrm{PCO}_{2}$ did not increase in aldosterone deficiency to the same magnitude as observed in adrenal intact controls during bicarbonate loading. These results taken together indicate, therefore, that the "acidification defect" that exists in selective aldosterone deficiency is complex. In addition, an important role for aldosterone in the

Table V. Papillary Ammonia Concentration $(\mu M)$

\begin{tabular}{lccccr}
\hline \multicolumn{1}{c}{ Group } & BCD & TCD & Loop & $\overline{\mathrm{CD}}$ & $\Delta\left[\mathrm{NH}_{3}\right]$ \\
\hline I CON & $59 \pm 8$ & $83 \pm 8$ & $122 \pm 11$ & $71 \pm 8$ & $67 \pm 15$ \\
II CMA & $135 \pm 30$ & $186 \pm 32$ & $265 \pm 41$ & $160 \pm 31$ & $105 \pm 28$ \\
III SAD & $171 \pm 36$ & $125 \pm 22$ & $192 \pm 29$ & $143 \pm 29$ & $49 \pm 20$ \\
$P$ (group II vs. I) & $<0.05$ & $<0.01$ & $<0.01$ & $<0.05$ & $<0.01$ \\
$P$ (group III vs. II) & NS & $<0.05$ & $<0.01$ & NS & $<0.01$
\end{tabular}

Values are means $\pm \mathrm{SE}$ for pooled data. $\overline{\mathrm{CD}}$, mean collecting duct $\mathrm{NH}_{3}$ concentration (average of base and tip), $\Delta\left[\mathrm{NH}_{3}\right]$, difference between loop and $\overline{C D}$ ammonia concentrations. regulation of acidification by nephron segments of the inner medulla is documented.

\section{Effects of CMA}

As reported previously by our laboratory (15) in control rats with intact adrenal glands, significant net transport of ammonia was not observed along the terminal collecting duct in nonacidotic ADX rats receiving chronic replacement of glucoand mineralocorticoids (Table III, group I). In this same group, the titratable acid index did not change between base and tip collecting duct, a finding in agreement with results reported previously by Buerkert and associates $(19,23)$. In comparison with these studies, however, the increase in $T F / P_{I n}$ between base and tip was greater in the present study, so that acid indices for both ammonia and titratable acid were quantitatively lower. This difference is most likely a result of the longer length of exposed papilla in our study ( $2.54 \mathrm{vs} .0 .8 \mathrm{~mm})$.

After development of chronic metabolic acidosis, net addition of ammonia between base and tip collecting duct was observed (group II-CMA, Table III, $P<0.01$ ). This finding is in agreement with results reported previously by our laboratory in adrenal intact acid-loaded rats (15). In addition, we now show the addition of net acid to this segment during this condition as well. The total ammonia concentration $(8.0 \pm 0.9$ to $17.3 \pm 3.3 \mathrm{mM}, P<0.01)$ and the amount of ammonia delivered to the loop of Henle (0.96 to $3.63 \mathrm{mM}$, Table IV and

Table VI. $\mathrm{PCO}_{2}$ Data: Bicarbonate-loaded Rats

\begin{tabular}{|c|c|c|c|c|c|}
\hline \multirow[b]{2}{*}{ Group } & \multicolumn{3}{|c|}{ Urine } & \multicolumn{2}{|c|}{$\begin{array}{c}\text { Papillary } \\
\text { collecting duct }\end{array}$} \\
\hline & $\mathrm{pH}$ & $\mathrm{PCO}_{2}$ & U-B $\mathrm{PCO}_{2}$ & BCD & TCD \\
\hline & & $m m H g$ & $m m H g$ & \multicolumn{2}{|c|}{$m m H g$} \\
\hline IV. $\mathrm{NaHCO}_{3}$-Loaded Controls & $7.80 \pm 0.02$ & $118 \pm 4$ & $70 \pm 4$ & $82 \pm 5$ & $118 \pm 3$ \\
\hline V. SAD-NaHCO ${ }_{3}$-Loaded & $7.90 \pm 0.03$ & $84 \pm 4$ & $41 \pm 4$ & $64 \pm 2$ & $80 \pm 3$ \\
\hline$P$ & NS & $<0.01$ & $<0.01$ & $<0.01$ & $<0.01$ \\
\hline
\end{tabular}

Data expressed as mean values \pm SE. "Urine" from right whole kidney by macroelectrode. U-B $\mathrm{PCO}_{2}$, urine minus arterial blood $\mathrm{PCO}_{2}$. $P$ compares groups IV and V. 

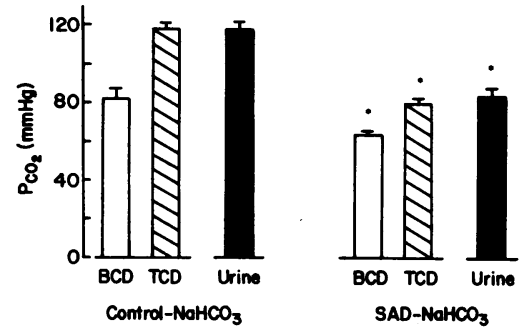

Figure 4. $\mathrm{PCO}_{2}$ data in bicarbonate-loaded controls (clear bars) and bicarbonate-loaded SAD rats (solid bars) for base and tip papillary collecting duct, and final urine. ${ }^{*} P<0.01$ for SAD vs. BL-controls.

Fig. $2, P<0.01)$ increased dramatically with metabolic acidosis. If the observed increase in ammonia delivery to the loop of Henle may be taken as a reflection of increased delivery out of the proximal tubule, then, this finding suggests that metabolic acidosis was associated with an increase in ammonia production and secretion in this segment, a finding compatible with a previous report from this $(24)$ and other $(25,26)$ laboratories. Finally, the concentration of ammonia $\left[\mathrm{NH}_{3}\right]$ at the loop of Henle increased after metabolic acidosis. Similarly, $\left[\mathrm{NH}_{3}\right]$ also increased at base and tip papilla.

\section{Effect of selective aldosterone deficiency}

In mineralocorticoid deplete, glucocorticoid replete rats a defect in acidification was clearly evident for several reasons. The most striking finding was the reduction in delivery of both titratable acid and ammonia to the base of the collecting duct as compared to adrenal intact rats with a comparable degree of metabolic acidosis (Tables III and IV, and Fig. 2). Moreover, net addition of ammonia was no longer observed along the papillary collecting duct (Fig. 2). Thus, total ammonia and titratable acid excretion decreased significantly with SAD (Table II). Since net acid excretion was reduced as a result of reduction in both total ammonia and titratable acid excretion in aldosterone deficiency, and since titratable acidity consists predominantly of phosphate, the possibility that mineralocorticoid deficient rats were phosphate depleted could be raised. This is unlikely in view of the observation that delivery of titratable acid delivery to the loop of Henle was actually higher in SAD rats than in ADX controls or CMA rats (Table IV). To the extent that loop delivery is a reflection of delivery out of the proximal tubule, phosphate depletion is unlikely. Since it is conceivable that inner medullary collecting duct acidification could be dependent on adequate delivery of nonammonia buffer for titration, we examined additionally, mineralocorticoid-deficient rats with base collecting duct delivery of titratable acid similar to controls (group III, $B$, Table III). Despite the increase in delivery of titratable acid addition of either total ammonia or net acid was not observed in this group. This finding contrasts with the results in acid-loaded rats. Moreover, a correlation between net addition or reabsorption of ammonia and titratable acid delivery was not evident in any of the groups examined (data not shown). Interestingly, in association with the reduction in total ammonia addition to the collecting duct in SAD rats, the gradient for passive diffusion of $\mathrm{NH}_{3}$ from loop of Henle to collecting duct was lower than that observed in acid-loaded rats (Table V). In addition to the defect in ammonia addition, urinary and papillary $\mathrm{PCO}_{2}$ during an alkaline diuresis was lower than in adrenal intact control rats (Table VI) indicating a reduction in hydrogen secretion in this segment. The magnitude of the reduction in papillary and urinary $\mathrm{PCO}_{2}$ is compatible with the reduction in $\mathrm{PCO}_{2}$ observed in other experimental models of distal renal tubular acidosis reported by our laboratory (27). Thus, total net acid excretion was reduced as a result of diminished ammonia delivery, which would allow a more rapid approach to the limiting $\mathrm{pH}$ gradient in the terminal nephron, but also as a result of diminished hydrogen secretion in the medullary collecting duct per se.

Micropuncture of the loop of Henle also demonstrated a reduction in the amount of total ammonia delivered in SAD rats as compared with acid-loaded adrenal intact animals (3.63-1.34 mM, Table IV and Fig. 3). To the extent that the amount of ammonia delivered to the loop reflects delivery out of the proximal tubule (24), this finding suggests that ammoniagenesis was decreased in SAD rats to levels incompatible with the degree of systemic metabolic acidosis present in these animals. Several explanations for this finding can be offered. First, rats in this group had mild but significant hyperkalemia (5.8 meq/liter, Table I) which has been reported to decrease ammoniagenesis by an as yet undefined but direct pathway (20). In both dogs (1) and human subjects (28) with mineralocorticoid deficiency renal ammonium excretion does not decrease when hyperkalemia is prevented. In this setting the reduction in net acid excretion can be accounted for as a result of a reduction in titratable acid excretion entirely. To investigate the role of potassium further, it would be necessary to prevent hyperkalemia in SAD rats and repeat the micropuncture studies. Such studies are planned as future areas of investigation by our laboratory. Recent in vitro microperfusion studies from our laboratory have demonstrated that an acute increase in bath and perfusate potassium concentration reduces net transport of total ammonia by the medullary thick ascending limbs of Henle perfused in vitro (29). When these findings are considered in light of the present results, it is interesting to hypothesize that hyperkalemia may have played a significant role in reducing $\mathrm{NH}_{4}{ }^{+}$transport by this segment. Decreased thick ascending limb reabsorption would serve to impair medullary trapping and thus excretion of $\mathrm{NH}_{4}{ }^{+}$. However, until reabsorption of ammonia by the thick ascending limb of rats with SAD can be examined as a function of bath potassium concentration, such a view must be considered speculative. In addition to the possible effects of hyperkalemia on transport and production of ammonia, aldosterone deficiency per se could mitigate the appropriate increment in ammoniagenesis which would be anticipated with metabolic acidosis, a view compatible with the in vitro data of Welbourne and Francoeur (30).

In summary, data obtained during aldosterone deficiency indicate a reduction in the amount of ammonia delivered to the loop of Henle appropriate for the degree of systemic acidosis. Concentration gradients for ammonia from loop of Henle to collecting duct were reduced quantitatively in conjunction with obliteration of ammonium addition between base and tip collecting duct. Finally, papillary $\mathrm{PCO}_{2}$ during bicarbonate loading, employed as a reliable and sensitive index of hydrogen secretory rate in this segment (14) was reduced significantly. Such data taken together are compatible with impaired hydrogen secretion in the papillary collecting duct.

Two mechanisms for defective papillary collecting tubule proton secretion have been suggested to exist in aldosterone deficiency. A direct reduction in the rate of proton secretion ("rate" defect) (31), or a decrease in proton secretion due to a reduction in sodium transport-dependent lumen negative voltage ("voltage" defect) (32-34). The latter defect would appear 
to reside exclusively in the cortical, not the medullary collecting tubule. In turtle urinary bladder aldosterone has been shown to increase the rate of $\mathrm{H}^{+}$secretion when the transepithelial $\mathrm{H}^{+}$concentration gradient is not limiting, but does not affect the protonmotive force of the pump (as defined by the transepithelial proton gradient required to nullify net $\mathrm{H}^{+}$secretion) (31). A "rate" defect, therefore, would be associated with preservation of the ability to achieve a normal minimal urine $\mathrm{pH}$ with systemic acidosis but low rates of proton secretion would be observed at higher luminal pH (35). Such appears to be the case in aldosterone deficiency as observed clinically $(22,35)$ and in experimental animal models $(1,4)$. Since deficiency of aldosterone should slow the rate of proton secretion, it follows that the urinary $\mathrm{PCO}_{2}$ during an alkaline diuresis (14) might be reduced. The findings in the present study (Table VI, Fig. 4) are consistent with this view. In contradistinction to this finding, a previous study (36) reported an increase in urinary $\mathrm{PCO}_{2}$ in response to bicarbonate infusion in rats with selective aldosterone deficiency which was indistinguishable from that observed in controls. While we are unable to explain these differences, several points should be made. First, adrenalectomized rats in the previous study (36) received daily intraperitoneal dexamethasone in large doses $(10 \mu \mathrm{g} \cdot 100$ $\mathrm{g}$ body $\left.\mathrm{wt}^{-1} \cdot \mathrm{d}^{-1}\right)$, while in the present study half this amount of glucocorticoid was administered by way of an osmotic minipump, a method shown previously to provide constant blood levels of the hormone (13). Second, in the latter study (36) systemic respiratory alkalosis $\left(\mathrm{PaCO}_{2}=27 \mathrm{mmHg}\right)$ was present. Third, urinary $\mathrm{PCO}_{2}$, even in sham controls receiving bicarbonate, was much lower in the previous study (53 $\mathrm{mmHg}$ ) than that routinely observed in bicarbonate loaded control rats in our laboratory $(100-120 \mathrm{mmHg})(14)(27)$. Compatible with our data, however, Robson et al. (37) have reported that mineralocorticoid (9- $\alpha$ fluorohydrocortisone) administration to adrenal intact rabbits increased the U-B $\mathrm{PCO}_{2}$ relative to controls undergoing a similar bicarbonate diuresis.

A reduction in papillary $\mathrm{PCO}_{2}$ relative to controls during bicarbonate loading has also been observed after chronic administration of either amiloride or lithium, and after unilateral ureteral obstruction (27). In these latter experimental models of defective acidification in the "distal" nephron, disequilibrium $\mathrm{pH}$ (a direct measure of $\mathrm{H}^{+}$secretion) was also shown to be reduced in the papillary collecting duct (27). Based on these previous findings we would predict that disequilibrium $\mathrm{pH}$ would also be reduced or obliterated in rats with aldosterone deficiency, although, such data are not available at present. In the defects associated with the postobstructed kidney and amiloride, a minimal urine $\mathrm{pH}$ cannot be achieved either with an acute acid load alone, or after superimposed sodium sulfate infusion (27). Since a normal minimal urine $\mathrm{pH}$ can be achieved in SAD in association with low buffer excretion, this finding in conjunction with the findings in the present study implies that a direct effect of aldosterone on $\mathrm{H}^{+}$secretion may be quantitatively more important than indirect effects mediated through voltage changes. In this regard, the recent preliminary findings of Hizon and Batlle (38) are of interest. By employing pharmacologic blockade of sodium-dependent acidification, these workers suggested that the sodium-independent effect of aldosterone on renal acidification is quantitatively more significant.

Thus, in summary, SAD in the rat is demonstrated in the present study to be associated with a multifactorial compro- mise in urinary acidification. First, presumably as a result of impaired ammonia production, ammonia delivery to the loop of Henle is reduced. Thus, the concentration gradient which would favor ammonia transfer to the inner medullary collecting duct is lower. Concomitantly, ammonia addition to the collecting duct between the base and tip of the papilla is not observed. A direct role for hyperkalemia in the reduction in delivery and medullary accumulation of ammonium, while possible, has not yet been established. Finally, urinary $\mathrm{PCO}_{2}$, and thus the rate of $\mathrm{H}^{+}$secretion in the medullary collecting tubule, is reduced, perhaps as a result of a decrease in pump activity as a direct effect of mineralocorticoid deficiency. Moreover, these data, taken together, emphasize that renal acidification by the inner medullary collecting tubule is under the influence of mineralocorticoid. The potential for systemic metabolic acidosis as a result of these defects in the setting of adrenal insufficiency could be amplified, theoretically, in the presence of renal insufficiency, a combination of events observed commonly in the clinical setting.

\section{Acknowledgments}

The authors thank Ms. Angie Pavlicek and Gail Pollard for secretarial assistance. Helpful suggestions during the course of this work were made by David W. Good.

These experiments were supported, in part, by National Institutes of Health grant R01 DK-30603.

\section{References}

1. Hulter, H. N., L. P. Ilnicki, J. A. Harbottle, and A. Sebastian. 1977. Impaired renal $\mathrm{H}^{+}$secretion and $\mathrm{NH}_{3}$ production in mineralocorticoid-deficient glucocorticoid-replete dogs. Am. J. Physiol. 232:(Renal Fluid Electrolyte Physiol. 1):F136-F146.

2. Wilcox, C. S., D. A. Cemeriki, and G. Giebish. 1982. Differential effects of acute mineralocorticoid and glucocorticosteroid administration on renal acid elimination. Kidney Int. 21:546-552.

3. Sebastian, A., J. M. Sutton, N. H. Hulter, M. Schambelan, and S. M. Poler. 1980. Effect of mineralocorticoid replacement therapy in renal acid-base homeostasis in adrenalectomized patients. Kidney Int. 18:762-769.

4. Hulter, H. N., J. H. Licht, R. D. Glynn, and A. Sebastian. 1979. Renal acidosis in mineralocorticoid deficiency is not dependent on $\mathrm{NaCl}$ depletion or hyperkalemia. Am. J. Physiol. 236:(Renal Fluid Electrolyte Physiol. 5):F283-F294.

5. Stokes, J. B., M. J. Ingram, A. D. Williams, and D. Ingram. 1981. Heterogeneity of the rabbit collecting tubule: Localization of mineralocorticoid hormone action to the cortical portion. Kidney Int. 30:341-347.

6. O'Neil R., and S. I. Helman. 1977. Transport characteristics of renal collecting tubules. Influences of DOCA and diet. Am. J. Physiol. 233:(Renal Fluid Electrolyte Physiol. 2):F544-558.

7. Stone, D. K., D. W. Seldin, J. P. Kokko, and H. R. Jacobson. 1983. Mineralocorticoid modulation of rabbit medullary collecting duct acidification: a sodium independent effect. J. Clin. Invest. 72:7783.

8. Richardson, R. M. A., and R. T. Kunau, Jr. 1982. Bicarbonate reabsorption in the papillary collecting duct: Effect of acetazolamide. Am. J. Physiol. 243:(Renal Fluid Electrolyte Physiol. 12):F74-F80.

9. DuBose, T. D., Jr., M. S. Lucci, R. J. Hogg, L. R. Pucacco, and N. W. Carter. 1983. Comparison of acidification parameters in superficial and deep nephrons of the rat. Am. J. Physiol. 244:(Renal Fluid Electrolyte Physiol 13):F497-503.

10. Prigent, A., M. Bichara, and M. Paillard. 1985. Hydrogen transport in papillary collecting duct of rabbit kidney. Am. J. Physiol. 248:(Cell Physiol. 17):C241-C246. 
11. Kleinman, J. G., S. S. Blumethal, J. H., Wiessner, K. L. Reetz, D. L. Leward, N. S. Mandel, G. S. Mandel, J. C. Garancis, and E. J. Cragoe, Jr. 1987. Regulation of $\mathrm{pH}$ in rat papillary tubule cells in primary culture. J. Clin. Invest. 80:1660-1669.

12. Higashihari, E., N. W. Carter, L. R. Pucacco, and J. P. Kokko. 1984. Aldosterone effects on papillary collecting duct $\mathrm{pH}$ profile of the rat. Am. J. Physiol. 246:(Renal Fluid Electrolyte Physiol. 15):F725F731.

13. Martin, R. S., W. J. Jones, and J. P. Hayslett. 1983. Animal model to study the effect of adrenal hormones on epithelial function. Kidney Int. 24:386-391.

14. DuBose, T. D., Jr. 1982. Hydrogen ion secretion by the collecting duct as a determinant of the urine to blood $\mathrm{PCO}_{2}$ gradient in alkaline urine. J. Clin. Invest. 69:145-156.

15. Good, D. W., C. R. Caflisch, and T. D. DuBose, Jr. 1987. Transepithelial ammonia concentration gradients in inner medulla of the rat. Am. J. Physiol. 252:(Renal Fluid Electrolyte Physiol. 21):F491-F500.

16. Jorgensen, K. 1957. Titrametric determination of the net excretion of acid/base in urine. Scand. J. Clin. Lab. Invest. 9:287-291.

17. Chan, J. C. M. 1972. The rapid determination of urinary titratable acid and ammonium and evaluation of freezing as a method of preservation. Clin. Biochem. 5:94-98.

18. Karlmark, B., P. Jaeger, H. Ein, and G. Giebisch. 1982. Coulometric acid-base titration in nanoliter samples with glass and antimony electrodes. Am. J. Physiol. 242:(Renal Fluid Electrolyte Physiol 11):F95-F99.

19. Buerkert, J., D. Martin, and D. Trigg. 1983. Segmental analysis of the renal tubule in buffer production and net acid formation. Am.J. Physiol. 244:(Renal Fluid Electrolyte Physiol 13):F442-F454.

20. Tannen, R. L., and J. McGill. 1976. The influence of potassium on renal ammonia production. Am. J. Physiol. 231:1178-1184.

21. Szylman, P., O. S. Better, C. Chaimowitz, and A. Rosler. 1976. Role of hyperkalemia in the metablic acidosis of isolated hypoaldosteronism. N. Engl. J. Med. 294:361-365.

22. Sebastian, A., M. Schambelan, H. N. Hulter, T. Maher, I. Kurtz, E. G., Biglieri, F. C. Rector, Jr., and R. Curtis Morris, Jr. 1985. Hyperkalemic renal tubular acidosis. In Renal Tubular Disorders. H. C. Gonick and V. M. Buckalew, Jr., editors. Marcel Dekker, Inc., New York. 307-356.

23. Buerkert J., D. Martin, and D. Trigg. 1982. Ammonium handling by superficial and juxtamedullary nephrons in the rat. Evidence for an ammonium shunt between the loop of Henle and the collecting duct. J. Clin. Invest. 70:1-12.

24. Good, D. W., and T. D. DuBose, Jr. 1987. Ammonia transport by early and late proximal convoluted tubules of the rat. J. Clin. Invest. 79:684-691.

25. Good, D. W., and W. B. Burg. 1984. Ammonia production by individual segments of the rat nephron. J. Clin. Invest. 73:602-610.

26. Nagami, G. T., C. M. Sonu, and K. Kurokawa. 1986. Ammonia production by isolated mouse proximal convoluted tubules perfused in vitro. Effect of metabolic acidosis. J. Clin. Invest. 78:124-129.

27. DuBose, T. D., Jr., and C. R. Caflisch. 1985. Validation of the difference in urine and blood $\mathrm{CO}_{2}$ tension during bicarbonate loading as an index of distal nephron acidification in experimental models of distal renal tubular acidosis. J. Clin. Invest. 75:1116-1123.

28. Sebastian, A., M. Schambelan, S. Lindenfeld, and R. C. Morris, Jr. 1977. Amelioration of metabolic acidosis with fludrocortisone therapy in hyporeninemic hypoaldosteronism. N. Engl. J. Med. 297:576583.

29. Good, G. W. 1987. Effects of potassium on ammonia transport by medullary thick ascending limb of the rat. J. Clin. Invest. 80:13581365.

30. Welbourne, T. C., and D. Francoeur. 1977. Influence of aldosterone on renal ammonia production. Am. J. Physiol. 233:(Endocrinol. Metab. Gastrointest. Physiol. 2):E56-E60.

31. Al-Awqati, Q., L. H. Norby, A. Mueller, and P. R. Steinmetz. 1976. Characteristics of stimulation of $\mathrm{H}^{+}$transport by aldosterone in turtle urinary bladder. J. Clin. Invest. 58:351-358.

32. Kurtzman, N. A. 1980. "Short-circuit" distal renal tubular acidosis. J. Lab. Clin. Med. 95:63-636.

33. Arruda, J. A. L., K. Subbarayuda, G. Dytko, R. Mola, and N. A. Kurtzman. 1980. Voltage-dependent acidification defect induced by amiloride. J. Lab. Clin. Med. 95:407-416.

34. Laski, M. E., and N. A. Kurtzman. 1983. Characterization of acidification in the cortical and medullary collecting tubule of the rabbit. J. Clin. Invest. 72:2050-2059.

35. DuBose, T. D., Jr., and R. J. Alpern. 1988. Renal tubular acidosis. In The Metabolic Basis of Inherited Disease. 6th Edition. C. R. Scriver, A. L. Beaudet, W. S. Sly, and D. Valle, editors. McGraw-Hill Book Co., New York. In press.

36. DiTella, P. J., B. Sodhi, J. McCreasy, J. A. L. Arruda, and N. A. Kurtzman. 1978. Mechanisms of the metabolic acidosis of selective mineralocorticoid deficiency. Kidney Int. 14:466-477.

37. Robson, W. L. M., M. L. Halperin, B. J. Stinebaugh, and M. B. Goldstein. 1981. Effect of mineralocorticoids on collecting duct hydrogen ion secretion in the rabbit. Can. J. Physiol. Pharmacol. 59:235-238.

38. Hizon, M., and D. C. Batlle. 1987. Role of aldosterone on renal acidification during chronic acid loading: Primacy of the $\mathrm{Na}^{+}$-independent effect. Am. Soc. Nephrol. 20:254a. (Abstr.) 